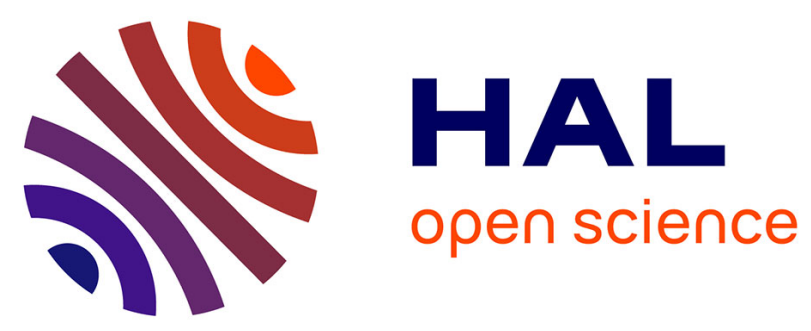

\title{
Glycemic response, satiety, gastric secretions and emptying after bread consumption with water, tea or lemon juice: a randomized crossover intervention using MRI
}

Daniela Freitas, François Boué, Mourad Benallaoua, Gheorghe Airinei, Robert Benamouzig, Evelyne Lutton, Laurène Jourdain, Rose-Marie Dubuisson, Xavier Maître, Luc Darrasse, et al.

\section{- To cite this version:}

Daniela Freitas, François Boué, Mourad Benallaoua, Gheorghe Airinei, Robert Benamouzig, et al.. Glycemic response, satiety, gastric secretions and emptying after bread consumption with water, tea or lemon juice: a randomized crossover intervention using MRI. European Journal of Nutrition, 2022, 10.1007/s00394-021-02762-2 . hal-03524413

HAL Id: hal-03524413

https://hal.inrae.fr/hal-03524413

Submitted on 13 Jan 2022

HAL is a multi-disciplinary open access archive for the deposit and dissemination of scientific research documents, whether they are published or not. The documents may come from teaching and research institutions in France or abroad, or from public or private research centers.
L'archive ouverte pluridisciplinaire HAL, est destinée au dépôt et à la diffusion de documents scientifiques de niveau recherche, publiés ou non, émanant des établissements d'enseignement et de recherche français ou étrangers, des laboratoires publics ou privés. 


\title{
Glycemic response, satiety, gastric secretions and emptying after bread consumption with water, tea or lemon juice: a randomized crossover intervention using MRI
}

\author{
Daniela Freitas ${ }^{1,4} \cdot$ François Boué $^{2,5} \cdot$ Mourad Benallaoua $^{2} \cdot$ Gheorghe Airinei $^{2} \cdot$ Robert Benamouzig $^{2}$. \\ Evelyne Lutton $^{1,6} \cdot$ Laurène Jourdain $^{3} \cdot$ Rose-Marie Dubuisson $^{3} \cdot$ Xavier Maître $^{3} \cdot$ Luc Darrasse $^{3}$. \\ Steven Le Feunteun ${ }^{1,7}$ (1)
}

Received: 26 July 2021 / Accepted: 25 November 2021

(c) The Author(s), under exclusive licence to Springer-Verlag GmbH Germany 2021

\begin{abstract}
Purpose Numerous studies, including our previous work with lemon juice, have reported that low-pH meals reduce the glycemic response to starchy foods. However, the underlying mechanism is not yet understood. Tea, for its polyphenol content, has also been investigated. The main objective of this research was to concurrently study gastric emptying, appetite perceptions and glycemic responses to bread consumed with water, tea, or lemon juice.

Methods In this randomized, crossover intervention, ten participants consumed equal portions of bread (100 g) with $250 \mathrm{~mL}$ of water, water-diluted lemon juice, or black tea at breakfast. Gastric volumes, blood glucose concentrations and appetite perceptions were alternately assessed over 180 min using magnetic resonance imaging, the finger-prick method and visual analogue scales, respectively.

Results Compared to water, lemon juice led to a 1.5 fold increase of the volume of gastric contents, $30 \mathrm{~min}$ after the meal (454.0 \pm 18.6 vs. $298.4 \pm 19.5 \mathrm{~mL}, \bar{x} \pm$ SEM $P<0.00001)$. Gastric emptying was also 1.5 times faster $(P<0.01)$. Conversely, lemon juice elicited a lower glycemic response than water (blood glucose concentrations at $\mathrm{t}=55$ min were $35 \%$ lower, $P=0.039$ ). Tea had no effect. Changes in appetite perceptions and gastric volumes correlated well, but with no significant differences between the meals.

Conclusions Lemon juice lowered the glycemic response and increased both gastric secretions and emptying rate. The results are compatible with the hypothesis that the reduction of the glycemic response is mainly due to the interruption of starch hydrolysis via the acid-inhibition of salivary $\alpha$-amylase.
\end{abstract}

Steven Le Feunteun

steven.le-feunteun@inrae.fr

1 Université Paris-Saclay, INRAE, AgroParisTech, UMR

SayFood, 78850 Thiverval-Grignon, France

2 CEFRED (Centre d'exploration Fonctionnelle et de Rééducation Digestive), Hôpital Avicenne, Service de gastro-entérologie, Bobigny Cedex, France

3 Université Paris-Saclay, CEA, CNRS, Inserm, BioMaps, Orsay, France

4 Present Address: Teagasc Food Research Centre, Moorepark, Fermoy, Ireland

5 Present Address: Laboratoire Léon Brillouin UMR 12, CNRS - CEA Université Paris-Saclay, 91191 Gif-sur-Yvette Cedex, France

6 Present Address: MIA, INRAE, ISC-PIF, 75013 Paris, France

7 Present Address: STLO, INRAE, Institut Agro, 35042 Rennes, France 
Trial registration number NCT03265392, August 29, 2017.

\section{Graphical abstract}

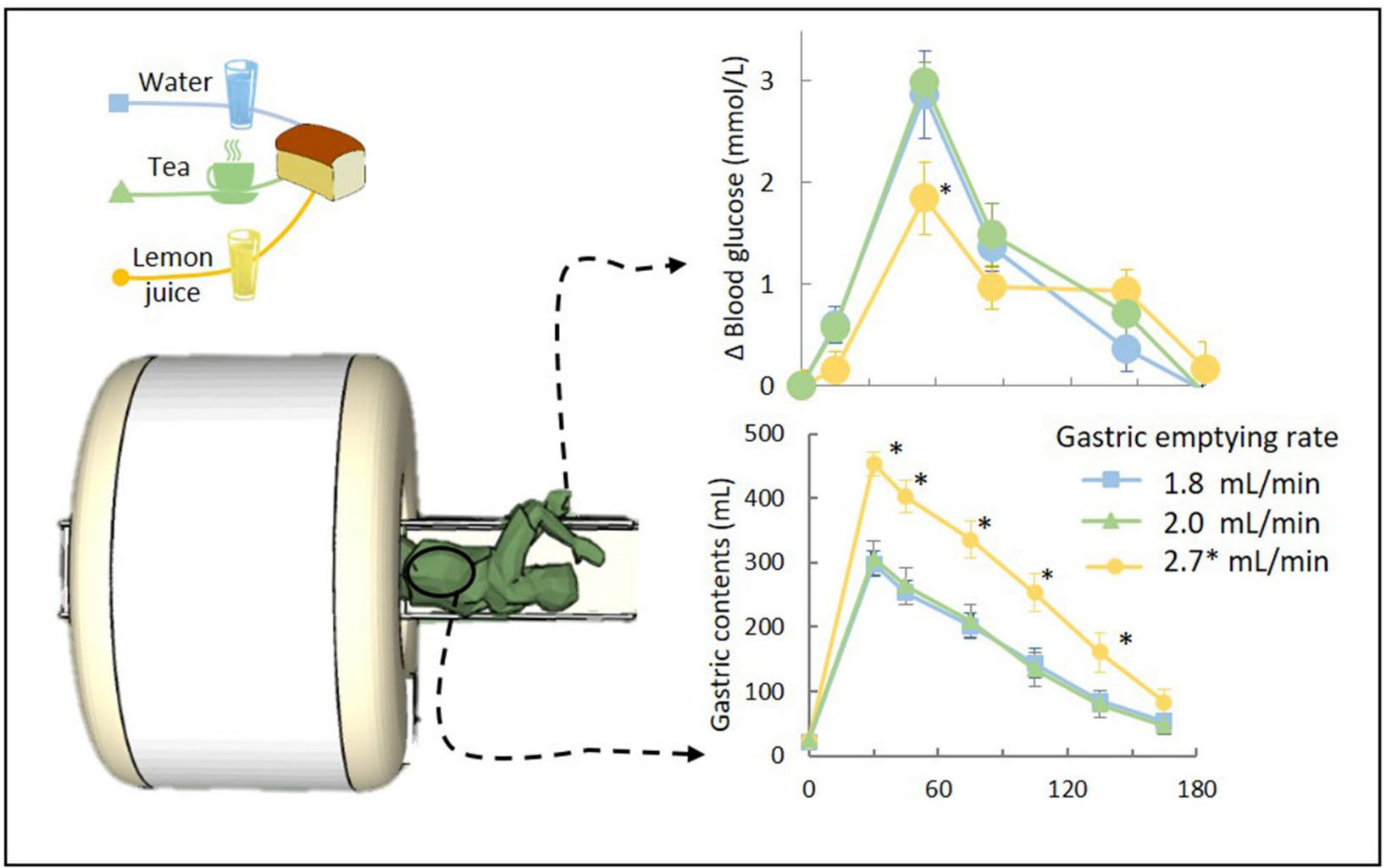

Keywords Glycemic index $\cdot$ Starch $\cdot$ Satiety $\cdot$ Meal pH $\cdot$ Salivary $\alpha$-amylase

\section{Abbreviations \\ AUC Area Under the Curve \\ BMI Body Mass Index \\ HAS Human salivary $\alpha$-amylase \\ VAS Visual Analogue Scale}

\section{Introduction}

Postprandial glycemic profiles are the net balance between the rates of appearance of exogenous (from food) and endogenous glucose and the rate of disappearance of glucose due to tissue uptake [1]. The rate of appearance of exogenous glucose has the strongest relationship with the postprandial glycemic response [1] but is, itself, the result of a complex interaction between numerous factors, among which, the glucose source, its digestion rate and the gastro-intestinal transit time.

The main source of exogenous glucose in our diets is starch, a polysaccharide entirely made up of glucose residues which makes up to $50 \%$ of the energy supply in human diets [2]. Starch digestion is initiated in the mouth by human salivary $\alpha$-amylase (HSA) [3] and continues in the stomach $[3,4]$ until the $\mathrm{pH}$ lowers to $3.0-3.8$ inactivating this enzyme $[5,6]$. The process is then resumed in the small intestine by pancreatic $\alpha$-amylase where it is completed by brush border enzymes and the final product, glucose, is absorbed [4]. Slowing down starch digestion through the inhibition of digestive amylases and/or glucosidases can slow down the uptake of starch-derived glucose, thereby lowering the glycemic response to starch-rich meals. A practical example is the administration of acarbose in the treatment of type 2 diabetes [7]. The conditions of each digestive step determine the vulnerabilities of each digestive stage. For example, oral and gastric phases are the most exposed to the different properties of a given food or meal, including their composition, initial $\mathrm{pH}$, macro- and micro-structural characteristics. However, of these, only the composition and micro-structure are likely to influence digestion in the small intestine because at this stage the $\mathrm{pH}$ is rapidly neutralized in the duodenum, and food macro-structure has already been largely disrupted. It is important to highlight that the first 
researchers who worked on this topic had already observed that gastric digestion seemed to play an important role in starch breakdown. The earliest reference to this seems to date back to 1876, when Reinhard van den Velden defended that gastric digestion should be separated into two stages the first being salivary (or amylolytic) digestion and the second peptic digestion [8]. The early literature on this topic seems, however, to have been forgotten. The emphasis is often put on the intestinal phase and studies on the role played by the gastric phase on starch breakdown and its implications for the glycemic response are to be carried over. Nonetheless, a combined analysis of later studies of the gastric environment suggests the contribution is far from negligible. Briefly, it has been reported that when food enters the stomach, gastric $\mathrm{pH}$ can rise well above the inactivation threshold of HSA (to 4.5-6.7) and that it can then take 75-107 min to reach $\mathrm{pH} \leq 2$ [9-11]. This indicates the existence of a large time-window during which HSA can continue hydrolyzing starch. At the same time, lowering the initial $\mathrm{pH}$ of the food shortens this period, offering an additional route for slowing down the uptake of starch-derived glucose. Members of our team have reproduced such digestive conditions in vitro observing that up to $20 \%$ and $50 \%$ of the starch respectively in pasta and bread was hydrolyzed during the gastric phase $[5,12]$. This is in agreement with in vivo studies of human [13] and porcine digestion [14]. The exploitation of this knowledge to slow down starch digestion has also been the subject of some of our previous work. Particularly, we have examined routes of HSA inactivation during gastric digestion in vitro and observed promising results via either an increase in acidity or polyphenol content [5, 15]. A growing body of evidence from randomized, controlled, crossover trials reinforces the viability of lowering postprandial glycemic responses to starchy foods by $20-50 \%$ with increased meal acidity. Previous works focused on pomegranate juice [16], vinegar [17-25], pickled foods [26] and acid bread fermentation [27-32]. Recently, we have also observed that lemon juice can significantly reduce (by 30\%) and delay (more than $35 \mathrm{~min}$ ) average peak blood glucose concentrations [33]. Different mechanisms have been proposed but there is no clear consensus yet [34-37]. The common denominators of the meals resulting in lower postprandial glycemia in these 18 independent studies were the main glucose source (starch) and the overall lower $\mathrm{pH}$ of the meal. Previously, we provided evidence that the lower glycemia could, at least in part, be explained by a premature interruption of starch digestion in the stomach [5, 15]. Conversely, a reduced and/ or delayed gastric emptying with acidic meals has also been identified as another candidate explanation [21], since gastric emptying rates influence the rate of nutrient absorption into the blood stream. Using magnetic resonance imaging (MRI), the main objective of the present work was therefore to study gastric emptying and blood glucose responses concurrently, to better understand the physiologic impact of combining starch-rich foods with beverages characterized by a rich polyphenol content or a low $\mathrm{pH}$.

\section{Subjects and methods}

This study was the second part of a two-branch investigation with the same test meals but with different participants and different measurements. The characteristics of the participants, the study details and the results presented here are exclusive to this part of the study. The clinical research protocol was approved by the ethics committee Lyon Sud-Est IV (ethical approval code: A 17-347; Lyon, France). All participants gave their written informed consent and this study was carried out in accordance with the Declaration of Helsinki and registered at Clinicaltrials.gov (NCT03265392).

\section{Participants}

Men (18-60 years old), in overall good health, with a normal body mass index (BMI) $\left(18-25 \mathrm{~kg} / \mathrm{m}^{2}\right)$ were eligible for this study. Women were not recruited for this part of the study to minimize the influence of varying insulin sensitivity [38], appetite control and eating behavior [39] during the menstrual cycle in healthy women. Another eligibility criterion was the ability to hold the breath for $25 \mathrm{~s}$ as this was required for certain MRI exams. Exclusion criteria included also any contraindications to MRI, medical interventions or surgeries requiring hospitalization within the previous 3 months, history of diabetes, use of any medication known to influence glucose metabolism, food consumption and/or appetite, allergies to any of the ingredients in the test meals, history of eating disorders, high alcohol consumption and having started/stopped smoking in the previous 3 months.

Recruitment was initiated through email and poster advertisements. Interested subjects were asked to answer an online pre-screening questionnaire and potentially eligible respondents were invited to an information meeting where they received oral and written information about the study. Subjects were informed that the aim of the study was to better understand the digestion of starch-rich meals when ingested in combination with commonly consumed beverages. Individuals who attended this meeting and expressed interest in participating in the trial were scheduled for a medical appointment at a later date, during which their physical health and eligibility were verified after the informed consent form was signed.

\section{Test meals}

Three meals were studied. Each test meal consisted of four slices $(100 \mathrm{~g})$ of crustless, wheat sandwich bread ("Harry's 
100\% mie Nature", Barilla France S.A.S, Boulogne-Billancourt, France) and two 125-mL glasses of either spring water (Mont Roucous ${ }^{\circledR}$, Lacaune-Les-Bains, France), black tea or lemon juice. The water meal was the reference meal. Tea (Lipton ${ }^{\circledR}$ Yellow Label ${ }^{\circledR}$ black tea, Unilever France, Rueil Malmaison, France) was freshly brewed $(1 \% \mathrm{w} / \mathrm{v})$ with spring water $\left(100{ }^{\circ} \mathrm{C}\right)$ and infused for $15 \mathrm{~min}$ before the tea bag was removed. Lemon juice was prepared by mixing $125 \mathrm{~mL}$ of commercial lemon juice (Lazy lemon, Polenghi, Milan, Italy) with $125 \mathrm{~mL}$ of spring water. The $\mathrm{pH}$ of tea was 6.7 and that of lemon juice was 2.3. Twenty frozen peas (Petits pois extra fins surgelés, Auchan Production, Villeneuve-d'Ascq, France), intended to be used as motility tracers in the MRI scans, were also included in each meal. The energy and nutrient content of the meals (estimated from the product labels) are presented in Table 1. The starch profile of the bread used in the present study had been previously characterized in our lab. From the total carbohydrates in the meal, bread provided $38.72 \pm 4.2 \mathrm{~g}$ of starch, of which $94.4 \pm 1.5 \%$ was digestible and $5.6 \pm 1.5 \%$ was resistant starch [40].

\section{Study design}

A randomized, crossover design was used. All subjects participated in three study sessions (separated by $\geq 2$ weeks) in which they received the three test meals for breakfast in a random sequence. Two volunteers requested to have two sessions scheduled within the 2 -week period due to availability constraints. The study visits took place at the Service Hospitalier Frédéric Joliot (Orsay, France).

An overview of the protocol followed during the test days is provided in Fig. 1A. Participants were asked to refrain from excessive alcohol consumption and intensive physical activity the evening before the study sessions. They arrived

Table 1 Energy and nutrient content of the meals

\begin{tabular}{llll}
\hline & Water & Tea & Lemon juice \\
\hline Energy content $(\mathrm{kcal})$ & 265.4 & 265.4 & 299.1 \\
Energy density $(\mathrm{kcal} / \mathrm{g})$ & 0.75 & 0.75 & 0.84 \\
Energy content $(\mathrm{kJ})$ & 1110 & 1110 & 1251 \\
Total fat $(\mathrm{g})$ & 3.9 & 3.9 & 3.9 \\
Total carbohydrate $(\mathrm{g})$ & 48.6 & 48.6 & 51.1 \\
Bread starch $^{a}(\mathrm{~g})$ & $38.7 \pm 4.2$ & & \\
Sugar $(\mathrm{g})$ & 6.2 & 6.2 & 8.7 \\
Fibre $(\mathrm{g})$ & 2.3 & 2.3 & 2.3 \\
Total protein $(\mathrm{g})$ & 7.8 & 7.8 & 8.3 \\
\hline
\end{tabular}

Each meal contained $100 \mathrm{~g}$ of white-wheat-bread, 20 peas and $250 \mathrm{~mL}$ of either water, tea or water diluted lemon juice

${ }^{a}$ In the meal, bread provided $38.7 \pm 4.2 \mathrm{~g}$ of total starch, including $36.6 \pm 0.6 \mathrm{~g}(94.4 \pm 1.5 \%)$ of digestible starch and $2.2 \pm 0.6 \mathrm{~g}$ $(5.6 \pm 1.5 \%)$ of resistant starch (i.e. as previously reported [40]) at the study site at 7:30 a.m., after an overnight fast of at least 10 hours. After verifying participants' compliance with pre-session requirements, they were asked to answer an MRI safety form and to fill a Visual Analogue Scale (VAS) to evaluate appetite perceptions. A baseline capillary blood glucose concentration measurement was performed twice and followed by a first MRI exam at 8:30 a.m.

Participants were asked to eat the bread and drink one $125 \mathrm{~mL}$ glass of the beverage first, and to swallow the peas at the end, without chewing, with the second $125 \mathrm{~mL}$ glass of beverage. Meals were always consumed in less than $15 \mathrm{~min}$, between 8:45 and 9:00 a.m. MRI exams, blood glucose measurements and VAS were performed at pre-defined timepoints over a period of 3 hours after the start of breakfast, as presented in Fig. 1A. The primary outcome of this study was the gastric emptying rate as determined from the gastric volumes assessed by the analysis of the 3D MRI exams.

\section{Measurements}

\section{MRI acquisition}

All MRI acquisitions were performed in a clinical, wholebody $1.5 \mathrm{~T}$ system using a 32-channel SENSE torso/cardiac coil (Phillips Healthcare, Best, The Netherlands). Participants were provided with earplugs for noise reduction. A respiratory sensor (Phillips Healthcare, Best, The Netherlands) was secured under the anterior coil array, on the epigastric region, with a Velcro strap. This sensor, connected to a wireless transmitter, was used to monitor respiratory movements. All subjects were examined in the right decubitus position, feet-in-first, following previous observations that this position adequately reflects the kinetics of gastric emptying in the seated position [41].

Each MRI exam was composed of a series of six acquisitions, each covering the complete gastric region (volume scans): one survey, one anatomic scan (25 s, breath-hold), three static motility scans ( $22 \mathrm{~s}$, breath hold) and one freemovement motility scan (1 min $25 \mathrm{~s}$, free breathing). An overview of the scans performed within each MRI exam is presented in Fig. 1B, and the corresponding MRI parameters are presented in Table 2.

The first MRI exam was conducted before meal consumption, and six others were performed $30,45,75,105,135$, and 165 min after the start of the meal (Fig. 1A). Participants exited the MRI after each exam (except between the 30and 45-min exams) for blood glucose measurements and/ or answering a VAS to evaluate appetite perceptions, after which they had a 15-20-min break. The coils were removed from their bodies for at least two of these breaks, unless participants preferred to keep them. During the breaks, participants were free to stand and take short walks within the facilities of the study center but were asked to refrain from 


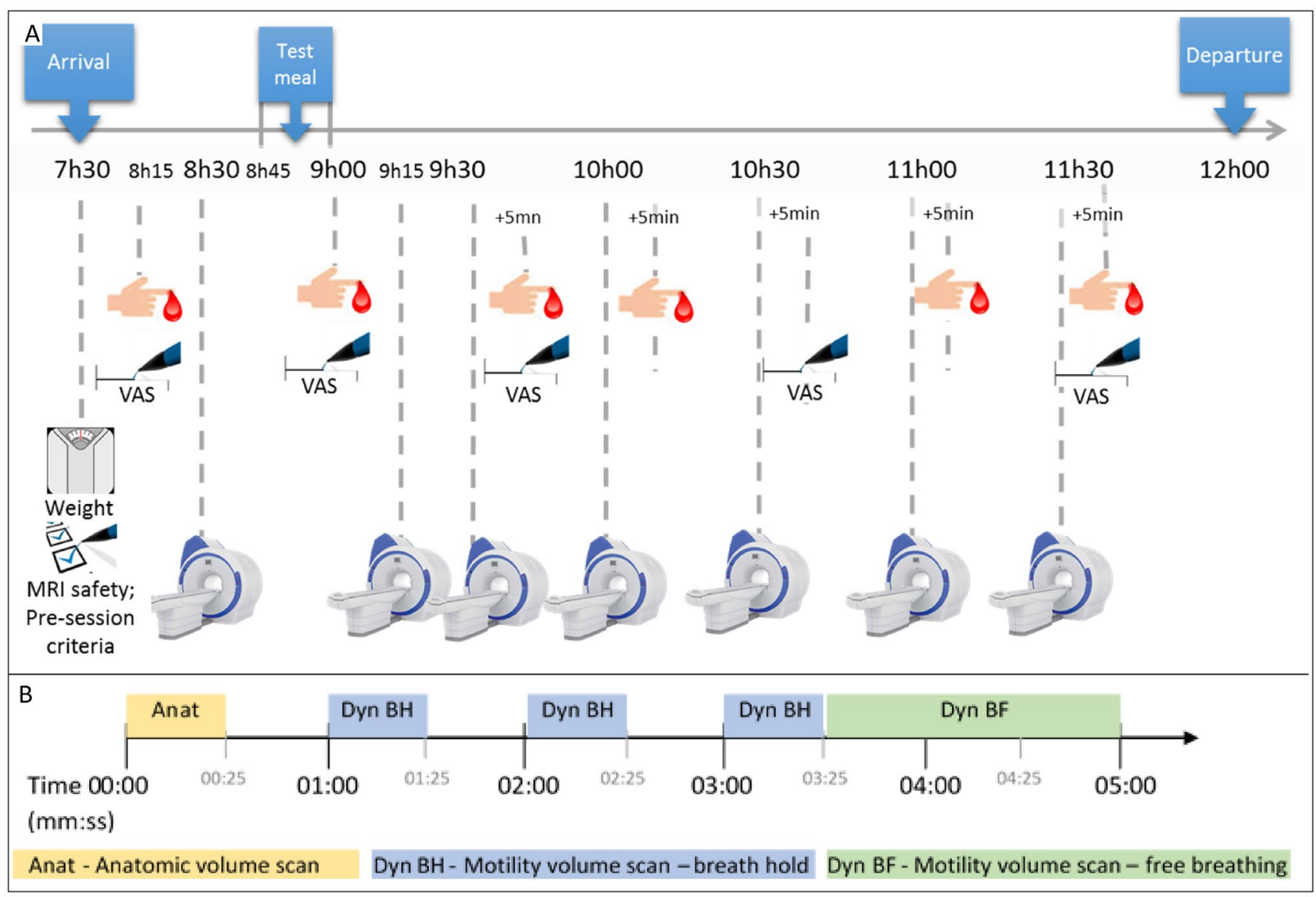

Fig. 1 Overviews of the study protocol (A) and of the sequence of the scans performed during each Magnetic Resonance Imaging (MRI) exam

Table 2 Parameters of the MRI sequences used for static and dynamic imaging of the gastric region

\begin{tabular}{lll}
\hline Imaging parameters & Anatomic volume scan breath hold & $\begin{array}{l}\text { Motility volume scans breath } \\
\text { hold and free breathing }\end{array}$ \\
\hline Weighting & $T 2$ & $T 1$ \\
Repetition time TR & $345 \mathrm{~ms}$ & $2.8 \mathrm{~ms}$ \\
Echo time TE & $60 \mathrm{~ms}$ & $0.89 \mathrm{~ms}$ \\
Matrix $(\mathrm{RL} \times \mathrm{AP} \times \mathrm{FH})$ & $192 \times 148 \times 72$ & $108 \times 86 \times 36$ \\
Voxel size & $(1.7 \times 1.7 \times 3) \mathrm{mm}^{3} \approx 8.6 \mu \mathrm{L}$ & $(3.0 \times 3.0 \times 6.0) \mathrm{mm}^{3} \approx 54 \mu \mathrm{L}$ \\
Scan time & $24.8 \mathrm{~s}$ & $3.5 \mathrm{~s} /$ dynamic \\
Flip angle & $90^{\circ}$ & $5^{\circ}$ \\
\hline
\end{tabular}

smoking, eating, drinking and any activities related to food or exercise.

Anatomic volume scan-breath hold A set of contiguous 2D slices of the abdominal region of the subject, with a high spatial resolution, was acquired to enable a $3 \mathrm{D}$ volume reconstruction of the stomach using a singleshot turbo spin echo (TSE) sequence. The echo time, TE, was $60 \mathrm{~ms}$, the repetition time, TR, was $345 \mathrm{~ms}$ and the acquisition bandwidth, BW, was $702 \mathrm{~Hz} /$ pixel. Interleaved acquisition mode was used to acquire a total of 72 axial slices covering a field of view of $(320 \times 253 \times 216) \mathrm{mm}^{3}$ (right- left $\times$ anterior-posterior $\times$ feet-head), with no gap. The acquisition matrix size was $192 \times 148$, hence a native in-plane resolution (pixel size) of $1.67 \times 1.71 \mathrm{~mm}^{2}$ and slice thickness of $3 \mathrm{~mm}$. Following interpolation, reconstructed voxel size was $0.83 \times 0.83 \times 3 \mathrm{~mm}^{3}$. The acquisition time was reduced with an acceleration SENSE factor of 2 in the anterior-posterior direction and with a partial coverage, $71 \%$, of the Fourier plane to fit into a single $25 \mathrm{~s}$ breath hold. 
Motility volume scan-breath hold A dynamic series of six consecutive 3D images of the abdominal region of the subject was acquired to assess gastric motility. The matrix size was $108 \times 86 \times 36$ and the acquisition voxel size was of $(2.96 \times 3.03 \times 6) \mathrm{mm}^{3}$ before interpolation to $(1.4 \times 1.4 \times 3) \mathrm{mm}^{3}$. A multi-shot turbo field echo (TFE) fast imaging mode was used with a TFE factor of 18 , $\mathrm{TE}=0.89 \mathrm{~ms}, \mathrm{TR}=2.8 \mathrm{~ms}$, and $\mathrm{BW}=500 \mathrm{~Hz} /$ pixel. The acquisition was accelerated by a SENSE factor of two in both anterior-posterior and feet-head directions. Each 3D set covered a field of view of $320 \times 261 \times 216 \mathrm{~mm}^{3}$ (rightleft $\times$ anterior-posterior $\times$ feet-head), with no gap. Each 3D image was scanned in $3.5 \mathrm{~s}$, leading to a total duration of $22 \mathrm{~s}$ for the whole dynamic series, within a single breath hold.

Motility volume scan-free breathing The gastric motility was additionally assessed while the participant was freely breathing over $1 \mathrm{~min}$ and $25 \mathrm{~s}$ with 24 consecutive $3 \mathrm{D}$ dynamic images with the same acquisition parameters as above (Table 2).

Image processing MRI scans were anonymized before processing with the participants' number and visit date. The correspondence with the consumed test meal was established only at the end. First, the gastric volumes were determined based on the anatomic volume scan. The region of interest (ROI) in each slice was manually drawn around the gastric contents with Matlab (MathWorks, Massachusetts, United States). The areas of the ROIs in all slices were then multiplied by the slice thickness and added up to determine the total volume of gastric contents. The chime and the air within the stomach were delineated and 3D reconstructions were created to illustrate their relative position and proportion. An example is provided in supplementary Figure S-1. Second, visual observations were performed onto the acquired motility volume scans.

Blood glucose Capillary blood samples obtained by finger prick were used to measure plasma glucose concentrations with a glucose meter (Accu-Chek Performa Blood glucose Meter, Roche Diabetes Care France, Meylan, France). Two consecutive measurements were performed in the fasted state to establish a baseline, and single measurements were then repeated $15,55,85,145$ and $180 \mathrm{~min}$ after the start of the test meal. Time-response curves were constructed and the area under the curve $(A U C)(\mathrm{mmol} \cdot \mathrm{min} / \mathrm{L})$ was calculated using the trapezoidal rule with fasting values as baseline. Negative areas (below the fasting baseline value) were ignored. Peak values ( $\mathrm{mmol} / \mathrm{L})$ and time-topeak (min) were also determined.

\section{Appetite perceptions}

Perceptions of hunger, satiety, fullness and prospective food consumption were quantified with validated VAS questionnaires [42]. Thirst and nausea were also assessed. VAS were composed of 100-mm lines with descriptors anchored at each end describing the extremes (e.g. "How hungry are you? Not at all/Extremely"). Participants rated each characteristic by placing a mark across each line on paper. They had no access to their previous ratings when completing a new VAS. Analysis of the VAS was conducted by measuring the horizontal distance from the left-hand end of the line to the mark indicated by the participant.

\section{Statistical analysis}

The number of subjects was determined using power calculations on the basis of previous work [43-47]. We calculated that a sample size of seven participants would allow us to detect a minimum difference of $15 \mathrm{~min}$ in the half-gastric emptying time with a 5\% level of significance and a power of $90 \%$, assuming a standard deviation (SD) of $7 \mathrm{~min}$. We increased the sample size to 10 to allow for a $25 \%$ dropout rate. This sample size is also in agreement with the international standard for the determination of the glycaemic index (GI) (ISO 26642:2010, a minimum of ten participants is recommended).

All data are presented as means \pm SEMs unless otherwise specified. All statistical analyses were performed in R (version 3.5.1) [48] with statistically significant effects accepted at the $95 \%$ level. The volumes of gastric content were analyzed using a mixed linear model for repeated measures (nlme package) with "time" (six levels: 30, 45, 75, 105, 135 , and $165 \mathrm{~min}$ ), and "meal" (three levels: water, tea, and lemon juice) as fixed factors, and replicates as random factor. Residual normality and variance homogeneity for each factor were verified using the Shapiro-Wilk test and the Levene test, respectively (lawstat package). Significant effects were observed for "time", "meal" and their interaction. Pairwise multiple comparisons of the means were therefore carried out using Tukey's test (lsmeans package) at each time point to determine which meal induced a significant effect. The residuals for the "time" variable in the blood glucose data set was heteroscedastic, and hence did not conform to the necessary conditions to use a mixed linear model for repeated measures. Therefore, blood glucose concentrations were analyzed similarly to other data (total emptying rate, $t_{50 \%}$, and AUCs in Table 3, VAS scores), using singlefactor ANOVAs at each time point to compare the effect of the meals, after verification of the normality of the data and of the residuals using the Shapiro-Wilk test, and the homoscedasticity using the Bartlett's test. When statistically 
Table 3 Gastric emptying and glucose responses for the water, tea and lemon juice meals

\begin{tabular}{lllll}
\hline & & Water & Tea & Lemon juice \\
\hline $\begin{array}{l}\text { Volume of gastric } \\
\text { contents at }\end{array}$ & $\mathrm{mL}$ & $298 \pm 20$ & $307 \pm 26$ & $454^{*} \pm 19$ \\
$\begin{array}{l}t=30 \mathrm{~min} \\
\text { Total emptying } \\
\text { rate }\end{array}$ & Change $\%^{2}$ & - & 3 & 52 \\
$t_{50 \%}$ & $\mathrm{~mL} / \mathrm{min}$ & $1.8 \pm 0.2$ & $2.0 \pm 0.2$ & $2.7^{*} \pm 0.1$ \\
& Change $\%^{2}$ & - & 12 & 50 \\
$\begin{array}{l}\text { Glucose AUC } \\
(0-85 \text { min })\end{array}$ & min & $84 \pm 5$ & $78 \pm 5$ & $85 \pm 5$ \\
& Change $\%^{2}$ & - & -7 & 1 \\
Glucose AUC & Change $\%{ }^{2}$ & - & 7 & -41 \\
$(0-165$ min $)$ & mmol $\cdot \mathrm{min} / \mathrm{L}$ & $198 \pm 23$ & $232 \pm 31$ & $159 \pm 21$ \\
\hline
\end{tabular}

Volume of gastric contents at $t=30 \mathrm{~min}$, estimated gastric emptying rate (up to blood glucose peak and total) and half emptying time $\left(t_{50 \%}\right)$, postprandial glucose areas under the curve $(A U C)$ from 0 to $85 \mathrm{~min}$ and 0 to $165 \mathrm{~min}$, for the three studied meals

All values are $\bar{x} \pm \operatorname{SEM}$ ( $n=10$ healthy adults). Values followed by an asterisk $(*)$ are significantly different from that obtained with water in the same row. Volume of gastric contents at $t=30 \mathrm{~min}$, total emptying rate and AUCs $(0-85 \mathrm{~min})$ for the lemon juice meal were significantly different than for the water meal $(P<0.00001,<0.01$ and $=0.03$, respectively)

${ }^{\text {a }}$ Change as a percentage of the bread + water reference meal

significant differences were detected, post hoc analysis was conducted using pairwise Tukey's test.

\section{Results}

\section{Participants' characteristics}

Ten participants have been recruited and completed the study. Their mean age was $26.8 \pm 6.7$ (range 18-47). All participants were healthy, with no history of diabetes and did not use any medications known to affect energy intake, appetite, gastrointestinal function or blood glucose, as confirmed by means of a full medical history and examination. All subjects had normal fasting glucose $(4.9 \pm 0.1 \mathrm{mmol} / \mathrm{L}$; $\overline{\mathrm{x}} \pm \mathrm{SEM})$ and normal body mass indexes $(20.7 \pm 18.3 \mathrm{~kg} /$ $\left.\mathrm{m}^{2} ; \overline{\mathrm{x}} \pm \mathrm{SD}\right)$.

\section{Gastric digestion}

All meals were consumed in a similar amount of time. Consumption times $(\overline{\mathrm{x}} \pm \mathrm{SEM})$ for the water tea and lemon juice meals were $12 \pm 1,13 \pm 1$ and $13 \pm 1 \mathrm{~min}$, respectively. Slice-images extracted from anatomic scans-breath hold of different participants and after different meals, are presented in Fig. 2A-C and show that gastric contents (contoured areas) provided enough contrast without the need for a contrast agent. The fact that similar contrast ranges were observed for all meals allowed image analysis to be performed without distinguishing between meals. Because the subjects were lying down in the right decubitus position, the chime was on their right and the air was confined into "pockets" above, on their left as mirrored in the MRI images (by convention). As explicit in the 3D segmented volumes of Fig. 2D, images show that the chime (red), as expected, remained confined to the lower gastric region while air (blue) filled the upper one throughout the MRI monitoring.

\section{Intragastric chime distribution}

Figures $2 \mathrm{~A}-\mathrm{C}$ and 3 show that intragastric chime was heterogeneous, with distinctive darker and brighter regions. Darker regions resulted from lower hydration (hence shorter $T_{2}$ ). They appeared either as separated, relatively scattered, single food boli (Fig. 3A), or in the form of bolus agglomerates (Fig. 3B and C). In some cases, boli retained their round shape until $165 \mathrm{~min}$ after breakfast (Fig. 3). As digestion proceeded, separated boli tended to cluster, forming larger agglomerates of increasingly lighter grey contrast (Fig. 3). Because lighter grey and white areas are indicative of higher moisture levels, this evolution can be attributed to an increasing proportion of digestive secretions in the chime. Between the first (30 $\mathrm{min})$ and last (165 min) scans, the total volume of the chime had been reduced by approximately $80 \%$ for all meals and contained mostly secretions (as indicated by the bright white contrasted regions). During this period, the ratio of air to chime also seemed to increase (Fig. 3).

\section{Mixing}

Typical dynamic images obtained with the motility volume scans are presented in Fig. 4.

Under breath hold, images were neat, allowing for a clear contrast of the peas consumed at the end of the meal that appeared bright white within the grey chime. At $30 \mathrm{~min}$ (i.e. 15-20 min after the meal ended), most peas seemed to be concentrated in the lower-mid region of the stomach and some were frequently observed in the bottom half of the stomach (in Fig. 4, this is indicated at 30 and 75 min by the white arrows). Because the peas were consumed last, their positioning reflects the efficiency of gastric movements in mixing gastric contents for this meal, as no layering effects were observed. It is also worth noting that some peas still retained their integrity (and also their contrast properties) 

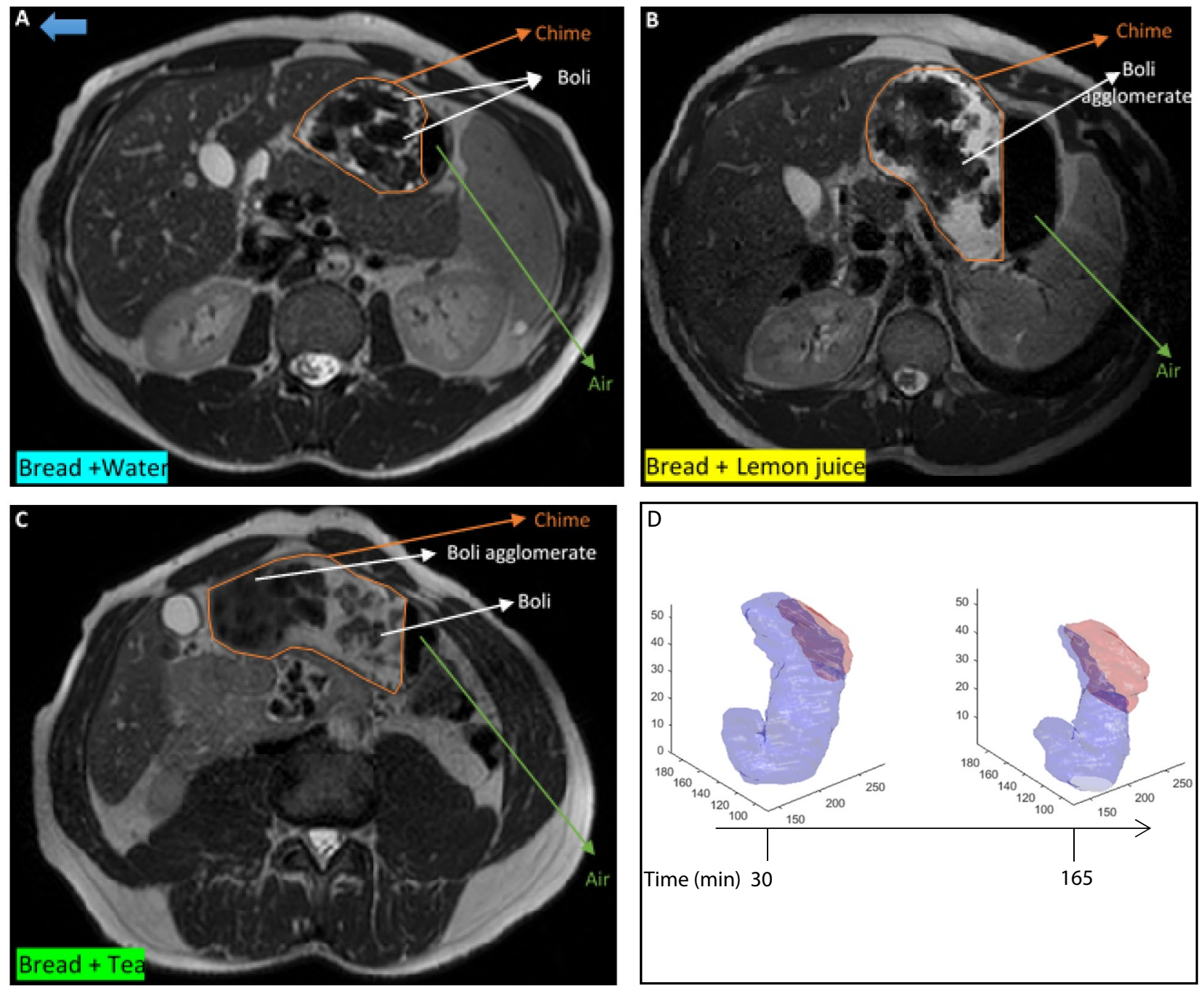

Fig. 2 A-C Typical MRI axial slice of the abdominal region of healthy adults during digestion of the bread meal, with 20 peas and $250 \mathrm{~mL}$ of either of water $(\mathbf{A})$, lemon juice $(\mathbf{B})$ or tea $(\mathbf{C})$. The images were extracted from scans conducted 30-45 min after the start of the meal. In the MRI scanner, participants were lying in right decubitus, hence, within the stomach, the chime was positioned towards that side (in different levels of grey) and the air was confined to a pocket

after exposure to the gastric environment for over $2.5 \mathrm{~h}$ (Fig. 4, $135 \mathrm{~min}$ and $165 \mathrm{~min}$ ).

Under free breathing conditions, the acquired motility volume scans turned out to be extremely blurry. Therefore, these data were discarded.

Volumes of gastric content. Average gastric volumes, over all participants, for each meal are presented as a function of time in Fig. 5A and summarized in Table 3 (the results obtained for each participant can be found in supplementary Figure S-2). There were no significant differences between the gastric volumes at baseline. During digestion, no statistically significant differences were found between above it. The thick blue arrow on the top left indicates de direction of gravity. The chime presented different nuances of grey. Bread boli were discernable as they appeared darker than the surrounding matter, they were scattered or in agglomerates. D Examples of 3D reconstructions of the stomach from MRI exams performed 30 and 165 min after the meal started. Blue and red colors illustrate the position and relative volumes of chime and air, correspondingly

the meals consumed with water or tea, while some clear differences were found with lemon juice. The volume of gastric contents $30 \mathrm{~min}$ after the start of the meal was about 1.5 times higher when bread was consumed with lemon juice than with water $(454.0 \pm 18.6 \mathrm{~mL}$ vs. $298.4 \pm 19.5 \mathrm{~mL}$, $\overline{\mathrm{x}} \pm$ SEM, with $P<0.0001)$ and remained significantly higher until 135 min after breakfast started $(P<0.0001$ from 45 to $105 \mathrm{~min}$, and $P=0.0167$ at $135 \mathrm{~min}$ ). Accordingly, the overall gastric emptying rate (estimated from the difference between the volume of gastric contents at $t=30$ and $165 \mathrm{~min}$ ) was also about higher with lemon juice than with water by the same 1.5 times factor $(2.7 \pm 0.1 \mathrm{~mL} / \mathrm{min}$ vs. 


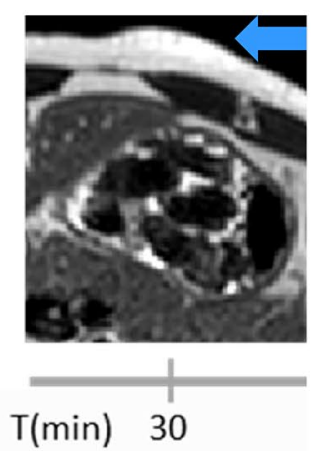

$T(\min ) \quad 30$

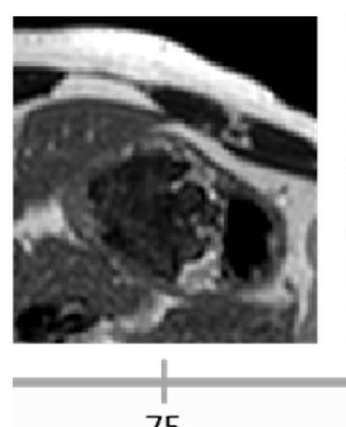

75

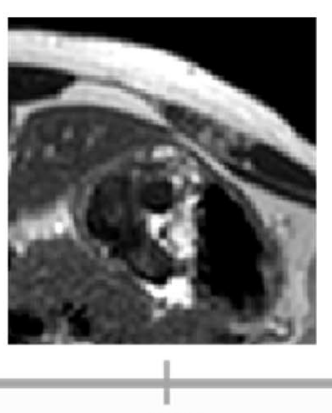

105

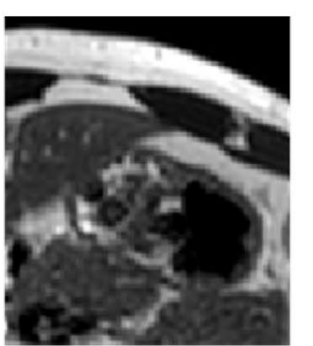

$+$

135

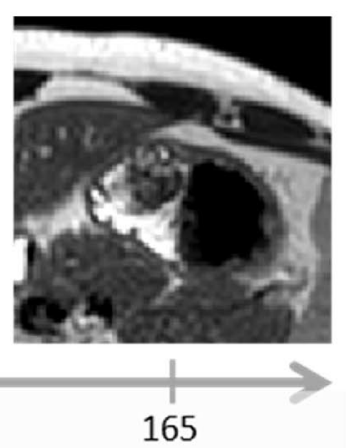

Fig. 3 Central axial slice of typical anatomic volume scans of the gastric region performed 30, 45, 75, 105, 135 and 165 min after the start of the water meal on one participant. The chime appears on the left in the stomach with visible boli or bolus agglomerates that appear

$1.8 \pm 0.2 \mathrm{~mL} / \mathrm{min}, \overline{\mathrm{x}} \pm \mathrm{SEM}, P<0.01)$. Due to that, the halfgastric emptying times, calculated using the gastric volume at $30 \mathrm{~min}$ as reference, were not significantly different between all meals, including lemon juice meals. They ranged between 78 and $85 \mathrm{~min}$ on average (Table 3). This is a central fact which will be discussed below.

\section{Blood glucose responses}

Average postprandial blood glucose responses elicited by the water, tea and lemon juice meals are presented in Fig. 5B. There were no significant differences in baseline blood glucose concentrations between the three test-meals $(P=0.21)$. Conversely, differences were clear on the evolution of the curve: lemon juice elicited a lower response in comparison with water, with statistically significant lower blood glucose concentrations observed at $t=55 \mathrm{~min}(P=0.039)$. No significant differences were found between water and tea. The mean area under the blood glucose curve $(A U C)$ and the equivalent changes as percentage of the corresponding results obtained with the water meal are presented in Table 3. The $A U C$ for the lemon juice meal was significantly lower between 0 and $85 \mathrm{~min}$ than for the water meal $(P=0.03)$ with a reduction of about $40 \%$. The $A U C$ between 0 and $165 \mathrm{~min}$ tended to be $30 \%$ lower for the lemon juice meal but this was not statistically significant $(P=0.14)$.

\section{Appetite perceptions}

The results of the participants' ratings for hunger, satiety, fullness, prospective food consumption, thirst and nausea are presented in Fig. 6A. There were no statistically significant differences in baseline ratings nor between the test meals at any given time-point. Hunger, thirst and prospective food consumption scores lowered immediately after the meal, increasing steadily afterwards. The opposite was observed darker than the surrounding. The air appears black on the left side of the stomach (to the right of the image). The subject was lying in right decubitus. The blue arrow on the top left indicates the direction of gravity

with the satiety and fullness ratings, which increased immediately after the meal and declined progressively after. As shown in Fig. 6B, the relationship between hunger, satiety, fullness, and prospective food consumption as a function of the volume of gastric contents tended to be linear, with slopes that tended to be slighter for the lemon meal in comparison with both water and tea meals.

\section{Discussion}

In this work, we have studied gastric digestion patterns and blood glucose responses after the consumption of meals containing equal servings of bread, peas, and an equal volume of either water, tea or lemon juice. The gastric phase of digestion was studied by MRI. This allowed to monitor stomach contents at a high level of detail including overall volumes, food bolus and individual food (pea) particles. Blood glucose concentration measurements were alternated with MRI scans and performed using the finger-prick method.

Water and tea led to undistinguishable results in terms of gastric emptying, blood glucose concentrations, and appetite perceptions. Significant differences were undoubtedly observed with lemon juice: higher gastric volumes during the first $135 \mathrm{~min}$, a higher gastric emptying rate, and an attenuation of the peak blood glucose concentration. This lower glycemic peak response with lemon juice is in full agreement with the results of the first part of this clinical study [33]. In that first part of the study, conducted with different participants and not involving MRI, the same meals were tested in a larger group (17 participants compared to 10 here) and more data points have been obtained ( 8 vs. 6 in the current study) during the same postprandial period. The glycemic peak could be identified for both water and tea, at around $30 \mathrm{~min}$ and $45 \mathrm{~min}$ after the start of the meal, i.e. at time-points that we did not cover in the present study 

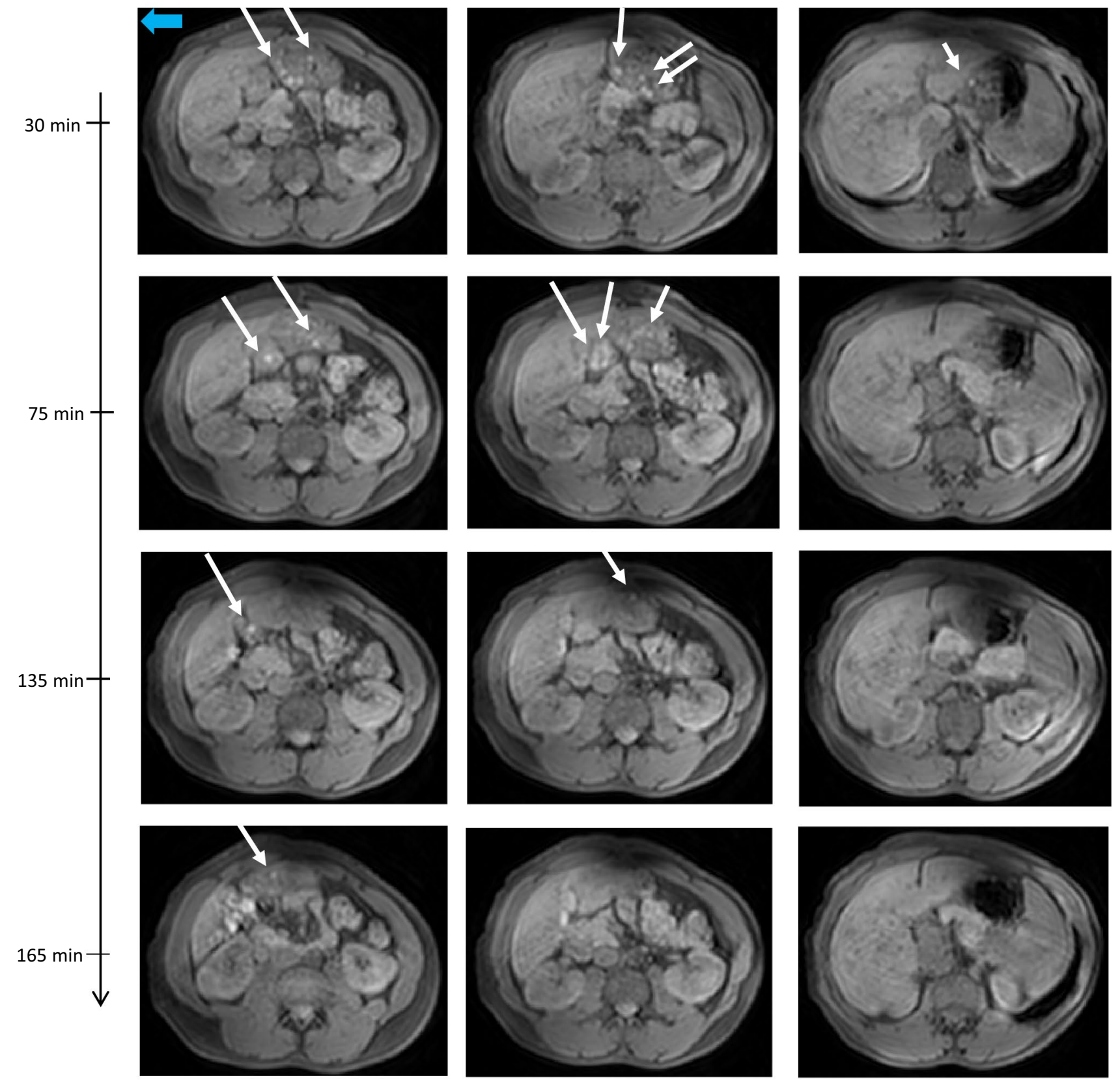

Fig. 4 Typical MR images of the motility volume dynamic scans performed 30, 75, 135 and 165 min after the start of the water meal on one participant. Slices shown in the two left columns correspond to the lower-mid region of the stomach, those in the right column correspond to the mid-upper part of the stomach. The chime appears in

part. The outcomes unambiguously showed that lemon juice decreased and delayed the glucose peak (by $30 \%$ and 35 min, respectively) [33]. Both present and former results are thus in agreement. grey with white dots that correspond to peas. The air appears in black and is visible on the left side of the stomach (right on the images) in the slices presented on the right column. White arrows $(\downarrow)$ indicate the position of the peas. The thick blue arrow on the top left indicates the direction of gravity

\section{Lemon juice influences gastric volume and emptying rate}

The ratio between the rates of gastric emptying with lemon juice and water (emptying rate about 1.5 times higher with lemon juice) was equivalent to the ratio between the initial gastric volumes (1.5 times higher for lemon juice). 
Fig. 5 Postprandial volume of gastric contents $(\mathbf{A})$ and incremental changes (opened triangle) in blood glucose concentrations (B) after consumption of three meals. The meals had equal volume and contained equal amounts of starch from white-wheat-bread which was consumed with water (filled square), tea (filled triangle) or lemon juice (filled circle). The * symbol indicates statistically significant differences between the meals containing lemon juice and water. Data points correspond to mean $\pm \mathrm{SEM} ; n=$ 10 healthy adults
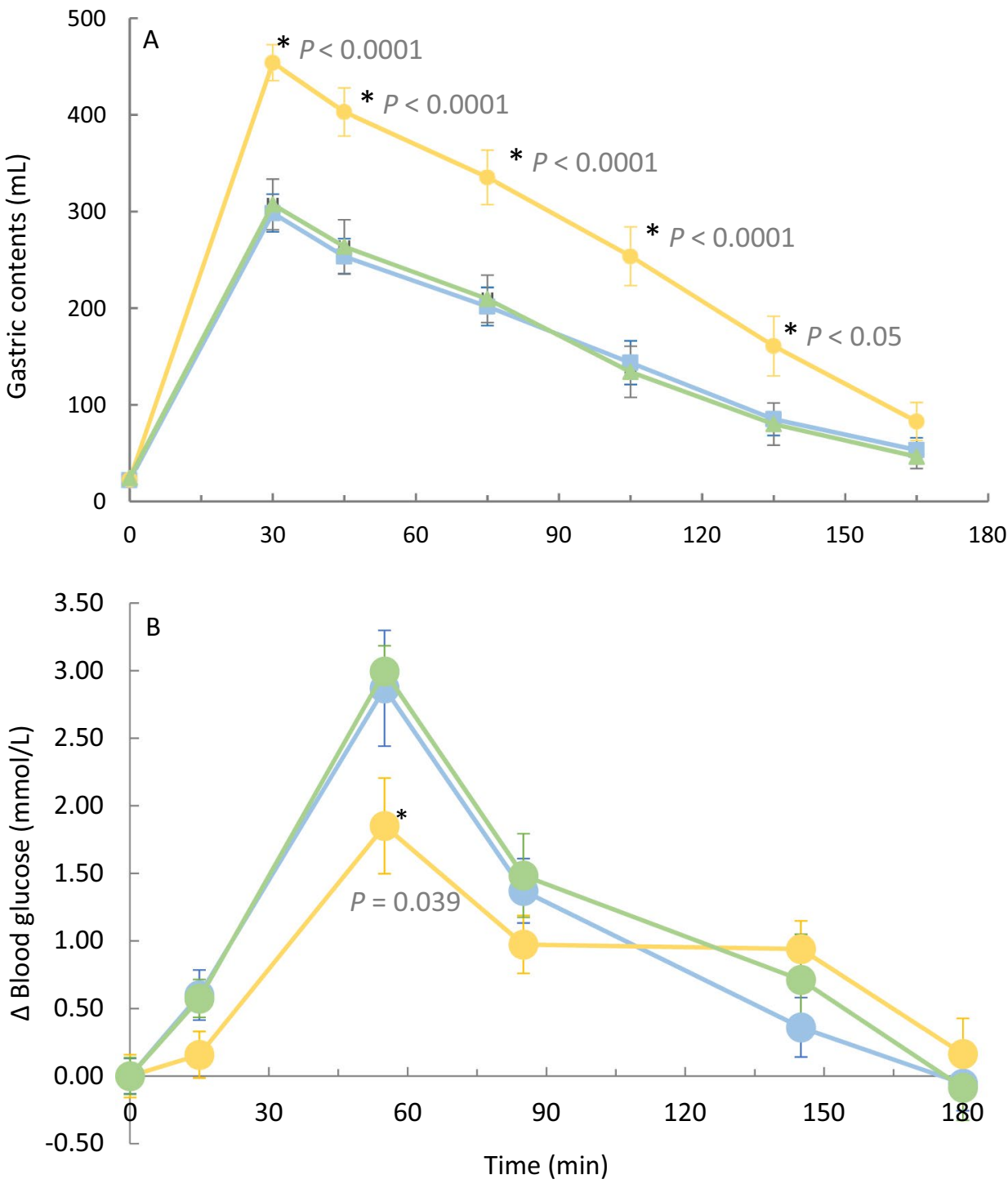

This led to similar gastric volumes at $t=165 \mathrm{~min}$, with no statistically significant differences observed (Fig. 5A). Formerly, a slower gastric emptying rate has been proposed as one of the driving mechanisms for the lower glycemic response to acidic foods when compared with their neutral-pH counterparts. This reasoning was supported by pioneering studies of Hunt and coworkers who attributed higher gastric volumes observed in response to various acids to a slower gastric emptying [49-51]. However, these observations were based on indirect measurements of gastric emptying and a single time point (all gastric contents were aspirated once, 9-19 min after the test-meal). Our results over the full digestion period do confirm that an increased meal acidity leads to an initially higher gastric volume, but they further show that a faster emptying rate compensates for this, leading to the same overall emptying times. The higher initial gastric volume with lemon juice is thus more likely due to increased digestive secretions. A first reason can be an increased salivary secretion, as acids, in particular citric acid, are among the most potent gustatory stimulus [52]. Previous studies have reported that the salivary flow during the chewing of bread is between 0.6 and $0.75 \mathrm{~mL} / \mathrm{min}[53,54]$, whereas flow rates ranging from 4 to $7 \mathrm{~mL} / \mathrm{min}$ have been reported after exposure to different concentrations of citric acid [52]. Additionally, a potential increase of gastric secretions cannot be ruled out either. It has been demonstrated that infusion of $100 \mathrm{mM} \mathrm{HCl}$ resulted in a threefold stimulation of pepsin secretion [55], though there is a lack of comparable studies in the fed state. Concerning the gastric emptying rate, our MRI results are very similar to the ones obtained by Goetze et al. [56], who showed that higher gastric secretions, as stimulated by intravenous infusion of pentagastrin, increased gastric volume at half-emptying time, but with no effect on the rate of gastric emptying per se. Note that in this study, they even questioned if there could be 
A

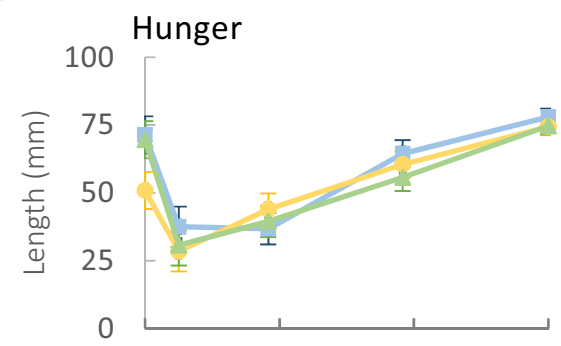

Satiety

Fullness
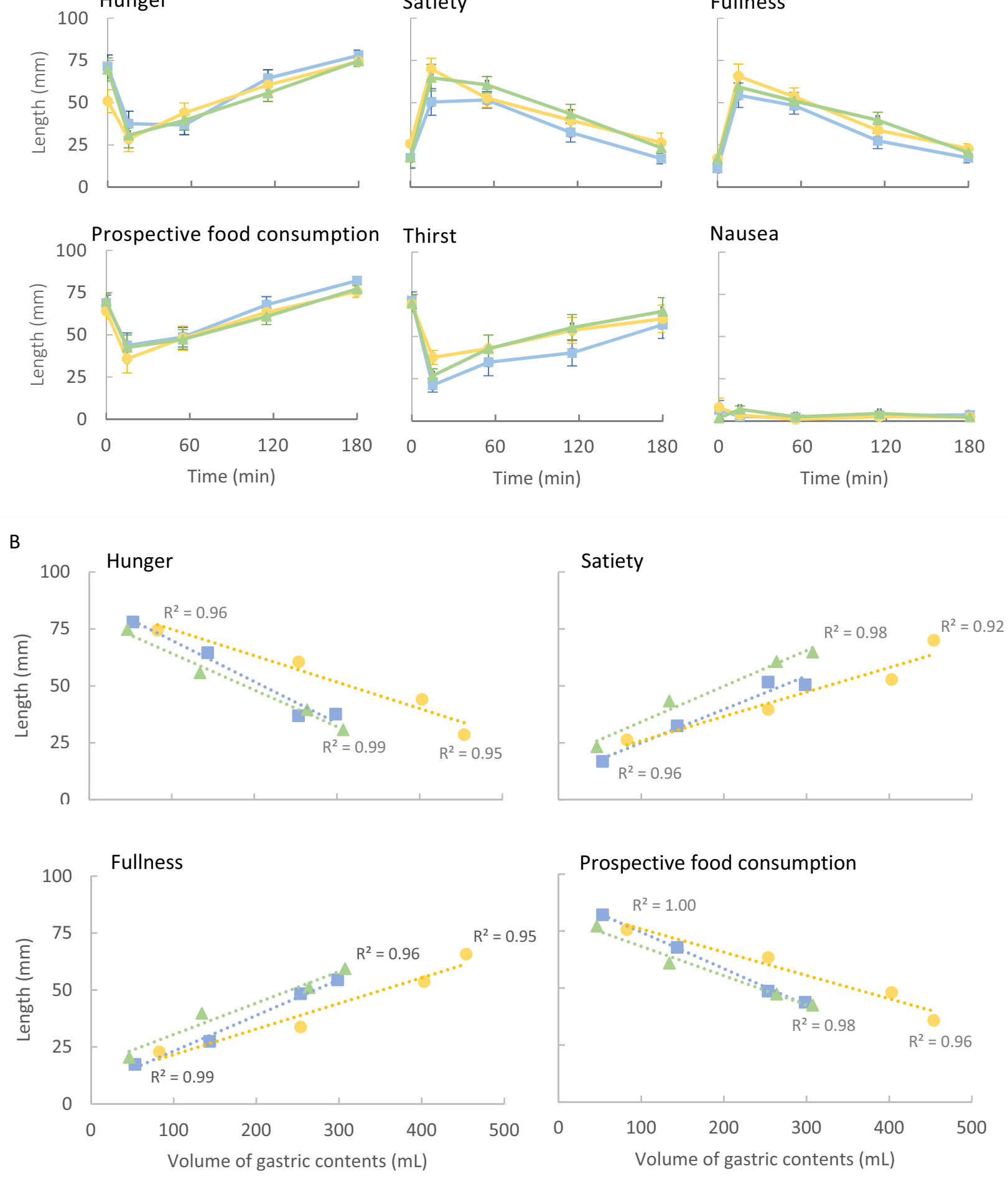

Prospective food consumption

Fig 6 Appetite perceptions and relationships with gastric volumes in response to equal amounts of starch from a white-wheat-bread consumed with either water (filled square), tea (filled triangle) or lemon juice (filled circle) $(n=10$ healthy adults). A Mean $( \pm$ SEM) incremental changes in ratings of hunger, satiety, fullness, prospective food consumption, thirst and nausea. B Relationships between appe- tite perceptions plotted against volume of gastric contents. Data were grouped by time point of measurement with a 5-10 min difference between acquisition times of $V A S$ and of volume of gastric contents. The sense of hunger and prospective food consumption decreased linearly, the senses of satiety and fullness increased linearly 
different effects on gastric physiology by endogenous acid production and exogenous administered acids.

Moreover, regarding the different emptying rates, it is important to note that subsequent work by Hunt's team [57] along with that of other research groups $[43,58,59]$ has pointed out the major importance of caloric density and how the stomach adapts to the physical and chemical properties of the meals to maintain a constant rate of calorie delivery to the small bowel.

Siegel and colleagues used scintigraphy to study the gastric emptying patterns of the solid and liquid components of a meal somewhat similar to that in our study [59]. In their study, the meal was composed of an egg sandwich (solid) and water (liquid). The egg and water were labelled differently and monitoring was initiated immediately after the meal was consumed. They observed that emptying of water started straightaway and at a fast rate, while the solid phase had an initial 31-min-long lag phase. After $30 \mathrm{~min}$, at least $90 \%$ of the solid phase was still in the stomach, while only about $50 \%$ of the liquid phase remained [59]. Although we had no MRI exams during the first $30 \mathrm{~min}$, considering the similarities between the composition of our meals and those in Siegel's article as well as the intra-gastric inhomogeneity observed here (Fig. 2A-C), it seems safe to assume a similar pattern in our study. Assuming equal lag phases for the solid fraction of all meals, if the caloric density of gastric contents is estimated from the gastric volume at $30 \mathrm{~min}$, the caloric density of the chime for the lemon juice meal would have been approximately $30 \%$ lower than with water (Table 4). Interestingly, gastric emptying appeared to have been adjusted accordingly as its higher rate with lemon juice (Table 3) led to similar gastric emptying rates in terms of $\mathrm{kcal} / \mathrm{min}$ ( 1.7 to $1.9 \mathrm{kcal} / \mathrm{min}$ ) (Table 4$)$. In absence of solid phase, a recent MRI study also reported that grapefruit juice $(\mathrm{pH}=3.3)$ and a glucose solution $(\mathrm{pH}=7.8)$ with equal caloric density were emptied out of the stomach at the same rate [60].

Numerous studies have reported the effect of low-pH meals on attenuating the glycemic response in healthy adults, but only three of them assessed gastric emptying and blood glucose concentrations concurrently [17, 21, 29]. In two of those, no differences were observed in the gastric emptying

Table 4 Estimated caloric density of the meal at $30 \mathrm{~min}$ and gastric emptying rate as a function of caloric density

\begin{tabular}{llll}
\hline & Water & Tea & Lemon juice \\
\hline $\begin{array}{l}\text { Caloric density of the chime } \\
\text { at } 30 \text { min }(\mathrm{kcal})^{\mathrm{a}}\end{array}$ & $1.0 \pm 0.1$ & $0.9 \pm 0.1$ & $0.7 \pm 0.1$ \\
$\begin{array}{l}\text { Emptying rate }(\mathrm{kcal} / \mathrm{min})^{\mathrm{b}} \\
\text { (1.7 }\end{array}$ & 1.7 & 1.9 & 1.8 \\
\hline
\end{tabular}

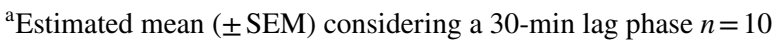

${ }^{b}$ Estimated according to caloric density at $30 \mathrm{~min}$ and the total gastric emptying rate (Table 3) rates, while a lower glycemic response for the lower $\mathrm{pH}$ meals was confirmed [17, 29]. In the third study [21] (in the presence of acetic acid), the glycemic response was lowered, by $36 \%$, but gastric emptying also appeared to have been $20 \%$ lower. However, this observation resulted from an indirect evaluation, based on monitoring blood paracetamol concentrations after participants consumed bread containing paracetamol: this opens the question as to whether the lower paracetamol concentrations derived from a slower release of paracetamol out of the bread (possibly induced by the slower enzymatic digestion due to the presence of acetic acid).

In summary, assuming equal lag phases for the solid fraction of all meals, the caloric density of gastric contents seemed to determine the gastric emptying rate leading to the delivery of nutrients to the small intestine at approximately the same rate.

\section{Can lemon juice reduce the glycemic response via an acid-induced inhibition of salivary a-amylase?}

The higher gastric volumes and emptying rate observed with the lemon juice meal imply that the chime emptied from the stomach had a lower carbohydrate concentration than with the water and tea meals. A dilution effect on the rate of glucose uptake in the small intestine could thus be a candidate explanation for the lower glycemic response in the presence of lemon juice. However, it has been shown that the glycemic response to various sugars, including glucose, rather tends to be higher for more diluted solutions [61]. The results and observations described above lead us to support a mechanism related with the premature acid-induced inhibition of salivary amylase, which we have previously put forward, and that can be recapitulated as follows. It is expected that lemon juice caused a premature (faster) acidification of the gastric contents, resulting in an earlier inactivation of salivary $\alpha$-amylase (the only amylolytic enzyme present during gastric digestion). Consequently, nutrient delivery to the small intestine, although quantitatively equivalent in terms of caloric potential, would likely have been qualitatively different because the extent to which nutrients had been digested was not the same. This is indeed possible, as shown in vitro: according to previous studies of ours, after 20-30 min of gastric digestion, as much as $70 \%$ of starch from the same bread and water meal can be released, with $45 \%$ thereof in the form of oligosaccharides (i.e. already resulting from hydrolysis). Conversely, for the lemon juice meal, only about $40 \%$ of the starch was released in vitro, with only approximately $10 \%$ thereof in the form of oligosaccharides at the gastric stage [15]. Controversial to the fact that in the many recent reviews on the attenuation of the glycemic response by low-pH meals, such effect is hardly addressed [34-37], our results support our previous hypothesis that the 
acid-inhibition of starch amylolysis by salivary $\alpha$-amylase is a key element in the lower glycemic response to low- $\mathrm{pH}$, starch-rich meals. Due to their low palatability, lemon juicebased beverages at the concentration used in this study might not be readily accepted by most consumers. However, the findings of this study illustrate the impact that food combination can have on postprandial glycemic responses and provide scientific grounds for future studies based on more easily acceptable equivalent approaches.

\section{Similar appetite perceptions despite different gastric processing and glycemic response}

It has been suggested that slower starch digestion leading to lower blood glucose concentrations could prolong satiety [62]. Satiety perceptions were also evaluated in four of the aforementioned studies reporting lower glycemic responses to acidic meals. The results were contradictory: two studies reported an increase in satiety [22,27], and two others found no effect $[29,30]$. Here, despite differences in the blood glucose response, we did not observe any effect of the test meals on satiety perceptions. It could be that we failed to observe an effect because this part of our work was not powered for this parameter. However, it should be noted that the first part of this study was adequately powered to investigate this parameter and has also shown no effect [33]. This agrees with the fact that in the literature, research on the effect of the glycemic response per se on appetite and satiety has been inconclusive [62]. More precisely, as explained by Wolever and colleagues [63], it is difficult to conceive test meals that elicit distinct glycemic responses and are, at the same time, controlled on all the other factors that could also influence satiety. Hence, results are often confounded by lack of control of the variables that could lead to an increased satiety. The authors [63] compared the effect of different glycemic responses to the exact same meal on satiety perceptions and also found no relationship. This is in agreement with our results.

\section{Conclusion}

We have studied the gastric phase of digestion, blood glucose response and appetite perceptions following the consumption of equal portions of bread with water, tea or lemon juice at breakfast. We had previously observed that black tea had no effect on the glycemic response to bread, but that lemon juice can attenuate it significantly. The present study, using MRI, corroborates these findings and further demonstrates that lemon juice can lead to a higher initial gastric volume that is compensated by a higher gastric emptying volumetric flux. The higher gastric volumes induced by lemon juice can be explained by an increase in the amount of digestive secretions. The compensation can result from the fact that similar rates of nutrient delivery to the small intestine took place with all meals, as also observed elsewhere. The kinetics of gastric emptying was well correlated with the appetite perceptions. However, despite important differences in the gastric volumes after the water and the lemon juice meals, there were no significant differences in appetite perceptions during their digestion. In summary, the reduction of the glycemic response by low-pH meals does not derive from a slower gastric emptying. It is better explained by faster inhibition of intra-gastric starch hydrolysis by salivary $\alpha$-amylase, due to faster $\mathrm{pH}$ decrease.

Supplementary Information The online version contains supplementary material available at https://doi.org/10.1007/s00394-021-02762-2.

Acknowledgements First of all, we thank the participants for their involvement. We thank Anders Sjödin and Thea Toft Hansen (University of Copenhagen) for their help during the preparation of this study. We thank Claire Gaudichon (INRA), Furio Brighenti (University of Parma), Luca Marciani (University of Nottingham) and Valérie Micard (Montpellier Supagro) for helpful discussions. We thank Amira Halabi and Ousmane Suwareh for their help using R software for statistical analysis. We thank our colleagues from the GMPA research unit (now UMR SayFood), Isabelle Souchon and Anne Saint-Eve, team leaders, for their constant valuable support and technical help, and Pascal Bonnarme, head of GMPA during this study. We thank Vincent Lebon, head of the Service Hospitalier François Joliot (SHFJ) for allowing us to conduct the MRI exams in its facilities. We also recall that this study was developed on the ground of former tests run at SHFJ also, jointly by all authors from GMPA and SHFJ-IR4M laboratories. Finally we also thank all of those who contributed to the successful completion of this part of the study, in particular the MRI technicians Laure Miche, Brigitte Mansalier, Béatrice Lhuillery et Laurence Tavassoli who performed the MRI exams.

Author contributions DF participated in the conceptualization of the study, conducted the research, analyzed and interpreted the data and wrote the manuscript. FB was involved in the conceptualization of the study, supervision of the study and interpretation. MB was involved in the conceptualization of the study. GA was involved in the conceptualization of the study. RB was the principal investigator and primary clinical advisor, and was involved in the conceptualization of the study. EL was involved in the conceptualization of the study and in the analytical procedures for the MRI scans. LJ assisted in the preparation of the MRI protocol and in the acquisition of MRI data. R-MD assisted in the preparation of the MRI protocol and in the acquisition of MRI data. $\mathrm{XM}$ was involved in the conceptualization of the study, established the MRI examination protocol and the analytical procedures for the MRI scans. LD was involved in the conceptualization of the study and supervision of the study. SLF was involved in the conceptualization of the study, supervision, data analysis and interpretation. All authors reviewed the manuscript and approved the final version.

Funding Daniela Freitas acknowledges funding from an IDEX ParisSaclay doctoral grant. This research did not receive any other specific grant from funding agencies in the public, commercial or not-for-profit sectors. 


\section{Declarations}

Conflict of interest The authors have no conflict of interest to declare.

Ethical approval Ethical approval by the ethics committee Lyon SudEst IV (Lyon, France), approval code: A 17-347.

\section{References}

1. Boers HM, Alssema M, Mela DJ, Peters HP, Vonk RJ, Priebe MG (2019) The rate of glucose appearance is related to postprandial glucose and insulin responses in adults: a systematic review and meta-analysis of stable isotope studies. J Nutr 149(11):1896-1903

2. Stylianopoulos CL (2012) Carbohydrates: Requirements and Dietary Importance. In: Caballero B, Allen LH, Prentice A (eds) Encyclopedia of human nutrition, vol 1,2nd edn. Academic press, Cambridge, pp 316-321

3. Bornhorst GM, Singh RP (2012) Bolus formation and disintegration during digestion of food carbohydrates. Compr Rev Food Sci Food Saf 11(2):101-118

4. Gropper SS, Smith JL (2013) Digestion of polysaccharides. In: Advanced nutrition and human metabolism. 6th edn. Cengage Learning, United States of America, p 70

5. Freitas D, Le Feunteun S (2018) Acid induced reduction of the glycaemic response to starch-rich foods: the salivary $\alpha$-amylase inhibition hypothesis. Food Funct

6. Fried M, Abramson S, Meyer J (1987) Passage of salivary amylase through the stomach in humans. Dig Dis Sci 32(10):1097-1103

7. Salvatore T, Giugliano D (1996) Pharmacokinetic-pharmacodynamic relationships of Acarbose. Clin Pharmacokinet 30(2):94-106

8. Davenport HW (1992) A history of gastric secretion and digestion: experimental studies to 1975. Oxford University Press, Oxford

9. Dressman JB, Berardi RR, Dermentzoglou LC, Russell TL, Schmaltz SP, Barnett JL, Jarvenpaa KM (1990) Upper gastrointestinal (GI) pH in young, healthy men and women. Pharm Res 7(7):756-761

10. Gardner JD, Ciociola AA, Robinson M (2002) Measurement of meal-stimulated gastric acid secretion by in vivo gastric autotitration. J Appl Physiol 92(2):427-434

11. Malagelada J-R, Go VLW, Summerskill WHJ (1979) Different gastric, pancreatic, and biliary responses to solid-liquid or homogenized meals. Dig Dis Sci 24(2):101-110

12. Freitas D, Le Feunteun S (2019) Oro-gastro-intestinal digestion of starch in white bread, wheat-based and gluten-free pasta: unveiling the contribution of human salivary $\alpha$-amylase. Food Chem 274:566-573

13. Bergeim O (1926) Intestinal chemistry: iii. Salivary digestion in the human stomach and intestines. Arch Intern Med 37(1):110-117

14. Martens BM, Bruininx EM, Gerrits WJ, Schols HA (2020) The importance of amylase action in the porcine stomach to starch digestion kinetics. Anim Feed Sci Technol 267:114546

15. Freitas D, Le Feunteun S (2019) Inhibitory effect of black tea, lemon juice, and other beverages on salivary and pancreatic amylases: What impact on bread starch digestion? A dynamic in vitro study. Food Chem 297:124885

16. Kerimi A, Nyambe-Silavwe H, Gauer JS, Tomás-Barberán FA, Williamson G (2017) Pomegranate juice, but not an extract, confers a lower glycemic response on a high-glycemic index food: randomized, crossover, controlled trials in healthy subjects. Am J Clin Nutr 106(6):1384-1393
17. Brighenti F, Castellani G, Benini L, Casiraghi M, Leopardi E, Crovetti R, Testolin G (1995) Effect of neutralized and native vinegar on blood glucose and acetate responses to a mixed meal in healthy subjects. Eur J Clin Nutr 49(4):242-247

18. Johnston CS, Buller AJ (2005) Vinegar and peanut products as complementary foods to reduce postprandial glycemia. J Am Diet Assoc 105(12):1939-1942

19. Johnston CS, Steplewska I, Long CA, Harris LN, Ryals RH (2010) Examination of the antiglycemic properties of vinegar in healthy adults. Ann Nutr Metab 56(1):74-79

20. Leeman M, Ostman E, Bjorck I (2005) Vinegar dressing and cold storage of potatoes lowers postprandial glycaemic and insulinaemic responses in healthy subjects. Eur J Clin Nutr 59(11):1266-1271

21. Liljeberg H, Björck I (1998) Delayed gastric emptying rate may explain improved glycaemia in healthy subjects to a starchy meal with added vinegar. Eur J Clin Nutr 52(5):368

22. Östman E, Granfeldt Y, Persson L, Björck I (2005) Vinegar supplementation lowers glucose and insulin responses and increases satiety after a bread meal in healthy subjects. Eur J Clin Nutr 59(9):983

23. Johnston CS, Kim CM, Buller AJ (2004) Vinegar improves insulin sensitivity to a high-carbohydrate meal in subjects with insulin resistance or type 2 diabetes. Diabetes Care 27(1):281-282

24. Liatis S, Grammatikou S, Poulia K-A, Perrea D, Makrilakis K, Diakoumopoulou E, Katsilambros N (2010) Vinegar reduces postprandial hyperglycaemia in patients with type II diabetes when added to a high, but not to a low, glycaemic index meal. Eur J Clin Nutr 64(7):727

25. Mitrou P, Raptis AE, Lambadiari V, Boutati E, Petsiou E, Spanoudi F, Papakonstantinou E, Maratou E, Economopoulos T, Dimitriadis G (2010) Vinegar decreases postprandial hyperglycemia in patients with type 1 diabetes. Diabetes Care 33(2):e27-e27

26. Sugiyama M, Tang A, Wakaki Y, Koyama W (2003) Glycemic index of single and mixed meal foods among common Japanese foods with white rice as a reference food. Eur J Clin Nutr 57(6):743

27. Bo S, Seletto M, Choc A, Ponzo V, Lezo A, Demagistris A, Evangelista A, Ciccone G, Bertolino M, Cassader M (2017) The acute impact of the intake of four types of bread on satiety and blood concentrations of glucose, insulin, free fatty acids, triglyceride and acylated ghrelin. A randomized controlled cross-over trial. Food Res Int 92:40-47

28. Lappi J, Selinheimo E, Schwab U, Katina K, Lehtinen P, Mykkänen H, Kolehmainen M, Poutanen K (2010) Sourdough fermentation of wholemeal wheat bread increases solubility of arabinoxylan and protein and decreases postprandial glucose and insulin responses. J Cereal Sci 51(1):152-158

29. Liljeberg H, Björck I (1996) Delayed gastric emptying rate as a potential mechanism for lowered glycemia after eating sourdough bread: studies in humans and rats using test products with added organic acids or an organic salt. Am J Clin Nutr 64(6):886-893

30. Liljeberg HG, Lönner CH, Björck IM (1995) Sourdough fermentation or addition of organic acids or corresponding salts to bread improves nutritional properties of starch in healthy humans. J Nutr 125(6):1503-1511

31. Maioli M, Pes GM, Sanna M, Cherchi S, Dettori M, Manca E, Farris GA (2008) Sourdough-leavened bread improves postprandial glucose and insulin plasma levels in subjects with impaired glucose tolerance. Acta Diabetol 45(2):91-96

32. Scazzina F, Del Rio D, Pellegrini N, Brighenti F (2009) Sourdough bread: Starch digestibility and postprandial glycemic response. J Cereal Sci 49(3):419-421

33. Freitas D, Boué F, Benallaoua M, Airinei G, Benamouzig R, Le Feunteun S (2021) Lemon juice, but not tea, reduces the glycemic 
response to bread in healthy volunteers: a randomized crossover trial. Eur J Nutr 60(1):113-122

34. Gobbetti M, Rizzello CG, Di Cagno R, De Angelis M (2014) How the sourdough may affect the functional features of leavened baked goods. Food Microbiol 37:30-40

35. Lim J, Henry CJ, Haldar S (2016) Vinegar as a functional ingredient to improve postprandial glycemic control-human intervention findings and molecular mechanisms. Mol Nutr Food Res 60(8):1837-1849

36. Poutanen K, Flander L, Katina K (2009) Sourdough and cereal fermentation in a nutritional perspective. Food Microbiol 26(7):693-699

37. Petsiou EI, Mitrou PI, Raptis SA, Dimitriadis GD (2014) Effect and mechanisms of action of vinegar on glucose metabolism, lipid profile, and body weight. Nutr Rev 72(10):651-661

38. Pulido JME, Salazar MA (1999) Changes in insulin sensitivity, secretion and glucose effectiveness during menstrual cycle. Arch Med Res 30(1):19-22

39. Dye L, Blundell J (1997) Menstrual cycle and appetite control: implications for weight regulation. Hum Reprod 12(6):1142-1151

40. Freitas D, Le Feunteun S, Panouillé M, Souchon I (2018) The important role of salivary $\alpha$-amylase in the gastric digestion of wheat bread starch. Food Funct 9(1):200-208

41. Treier R, Steingoetter A, Weishaupt D, Goetze O, Boesiger P, Fried M, Schwizer W (2006) Gastric motor function and emptying in the right decubitus and seated body position as assessed by magnetic resonance imaging. J Magn Reson Imaging 23(3):331-338

42. Flint A, Raben A, Blundell J, Astrup A (2000) Reproducibility, power and validity of visual analogue scales in assessment of appetite sensations in single test meal studies. Int J Obes 24(1):38

43. Kwiatek MA, Menne D, Steingoetter A, Goetze O, Forras-Kaufman Z, Kaufman E, Fruehauf H, Boesiger P, Fried M, Schwizer W (2009) Effect of meal volume and calorie load on postprandial gastric function and emptying: studies under physiological conditions by combined fiber-optic pressure measurement and MRI. Am J Physiol 297(5):G894-G901

44. Marciani L, Gowland PA, Spiller RC, Manoj P, Moore RJ, Young P, Fillery-Travis AJ (2001) Effect of meal viscosity and nutrients on satiety, intragastric dilution, and emptying assessed by MRI. Am J Physiol 280(6):G1227-G1233

45. Marciani L, Pritchard SE, Hellier-Woods C, Costigan C, Hoad C, Gowland PA, Spiller RC (2013) Delayed gastric emptying and reduced postprandial small bowel water content of equicaloric whole meal bread versus rice meals in healthy subjects: novel MRI insights. Eur J Clin Nutr 67(7):754

46. Deane AM, Nguyen NQ, Stevens JE, Fraser RJ, Holloway RH, Besanko LK, Burgstad C, Jones KL, Chapman MJ, Rayner CK (2010) Endogenous glucagon-like peptide-1 slows gastric emptying in healthy subjects, attenuating postprandial glycemia. J Clin Endocrinol Metab 95(1):215-221

47. Feinle C, Kunz P, Boesiger P, Fried M, Schwizer W (1999) Scintigraphic validation of a magnetic resonance imaging method to study gastric emptying of a solid meal in humans. Gut 44(1):106-111

48. RCoreTeam (2016) R: a language and environment for statistical computing. R Foundation for Statistical Computing, Vienna

49. Hunt J, Knox M (1962) The regulation of gastric emptying of meals containing citric acid and salts of citric acid. J Physiol 163(1):34-45

50. Hunt J, Knox M (1969) The slowing of gastric emptying by nine acids. J Physiol 201(1):161-179

51. Hunt J, Knox M (1972) The slowing of gastric emptying by four strong acids and three weak acids. J Physiol 222(1):187-208

52. Watanabe S, Dawes C (1988) The effects of different foods and concentrations of citric acid on the flow rate of whole saliva in man. Arch Oral Biol 33(1):1-5

53. Carreira L, Midori Castelo P, Simões C, Capela e Silva F, Viegas C, Lamy E (2020) Changes in salivary proteome in response to bread odour. Nutrients 12(4):1002

54. Lamy E, Santos V, Barrambana S, Simões C, Carreira L, Infante P, Capela e Silva F (2021) Saliva protein composition relates with interindividual variations in bread sensory ratings. Starch-Stärke 73(1-2):2000052

55. Johnson LR (1973) Effect of gastric mucosal acidification on the action of pepsigogues. Am J Physiol 225(6):1411-1415

56. Goetze O, Treier R, Fox M, Steingoetter A, Fried M, Boesiger P, Schwizer W (2009) The effect of gastric secretion on gastric physiology and emptying in the fasted and fed state assessed by magnetic resonance imaging. Neurogastroenterol Motil 21(7):725-e 742

57. Hunt J, Smith J, Jiang C (1985) Effect of meal volume and energy density on the gastric emptying of carbohydrates. Gastroenterology 89(6):1326-1330

58. Calbet J, MacLean D (1997) Role of caloric content on gastric emptying in humans. J Physiol 498(2):553-559

59. Siegel J, Urbain J, Adler L, Charkes N, Maurer A, Krevsky B, Knight L, Fisher R, Malmud L (1988) Biphasic nature of gastric emptying. Gut 29(1):85-89

60. Grimm M, Koziolek M, Saleh M, Schneider F, Garbacz G, Kühn J-P, Weitschies W (2018) Gastric emptying and small bowel water content after administration of grapefruit juice compared to water and isocaloric solutions of glucose and fructose: a fourway crossover mri pilot study in healthy subjects. Mol Pharm 15(2):548-559

61. Sievenpiper JL, Jenkins DJ, Josse RG, Vuksan V (2000) Dilution of the 75-g oral glucose tolerance test increases postprandial glycemia: implications for diagnostic criteria. CMAJ 162(7):993-996

62. Blaak E, Antoine JM, Benton D, Björck I, Bozzetto L, Brouns F, Diamant M, Dye L, Hulshof T, Holst J (2012) Impact of postprandial glycaemia on health and prevention of disease. Obesity Rev 13(10):923-984

63. Wolever TM, Leung J, Vuksan V, Jenkins AL (2009) Day-today variation in glycemic response elicited by white bread is not related to variation in satiety in humans. Appetite 52(3):654-658 